\title{
A maternidade para um CUIdado de si: Desafios PARA A CONSTRUÇÃO DA EQUIDADE DE GÊNERO
}

\author{
Silvana Maria BITENCOURT*
}

\begin{abstract}
RESUMO: A crescente inserção feminina na educação superior e no mercado de trabalho nas últimas décadas colabora para reforçar alguns dilemas na construção da equidade de gênero, no que se refere ao uso do tempo para as mulheres estudarem, trabalharem, cuidarem da família e cuidarem-se. Partindo desta perspectiva, este trabalho tem como objetivo identificar como as mulheres universitárias lidam com a maternidade e a construção da carreira durante a fase da graduação. Para isto realizouse trabalho de campo em dois cursos de graduação e foram realizadas dez entrevistas semiestruturadas com estudantes em caráter de profundidade. Concluímos que a maioria das mães apresenta dificuldades em conciliar maternidade e estudos, algumas delas pensam em desistir por não contar com uma rede de apoio, assim como não há políticas públicas que reconheçam a participação da mulher mãe nas universidades brasileiras.
\end{abstract}

PALAVRAS- CHAVE: Maternidade. Cuidado. Desigualdade de gênero. Equidade de gênero.

Introdução

A crescente inserção feminina na educação superior e no mercado de trabalho nas últimas décadas colabora para reforçar alguns dilemas, que ainda comprometem a construção da equidade de gênero no que toca as condições sociais, culturais e econômicas para as mulheres estudarem, trabalharem, cuidarem da família e cuidaremse (ARAÚJO, 2006; O’REILLY, 2005; SORJ et al 2007).

\footnotetext{
* UFMT - Universidade Federal de Mato Grosso. Instituto de Ciências Humanas e Sociais. Programa de Pós-Graduação em Sociologia. Campus Cuiabá. Cuiabá - MT - Brasil. 78068-401 silvana_bitencourt@yahoo.com.br. https://orcid.org/0000-0002-3183-373X.
} 
A maternidade ainda não foi um assunto superado pelas questões feministas, pois as diversas desigualdades de gênero detectadas em várias relações sociais afirmam que elas têm assumido a maior parte do trabalho doméstico e o cuidado dos filhos, logo, enfrentado dificuldades em investir em uma carreira profissional (BITENCOURT, 2013).

Assim, a maternidade necessita de uma análise de gênero, a fim de compreender por que as mulheres são as mais prejudicadas quando o dilema é conciliar maternidade e carreira, ou seja, vida profissional e pessoal (ARAÚJO, 2006).

Partindo da perspectiva do ser mulher na contemporaneidade, este trabalho tem por objetivo verificar como as estudantes de Ciências Sociais e Medicina lidam com a maternidade e o cuidado de si. Considerando que a universidade brasileira não tem apresentado uma política pública que insira diretamente as mulheres mães, pois o número de creches nas universidades não consegue suprir a grande demanda das estudantes mães, especialmente as trabalhadoras e de baixa renda.

Em relação à metodologia, realizou-se trabalho de campo em dois cursos de graduação (Ciências Sociais e Medicina) e foram realizadas dez entrevistas semiestruturadas em caráter de profundidade com estudantes mães.

O trabalho de campo foi realizado de julho de 2016 a junho de 2017, sendo que no curso de Medicina as entrevistas foram realizadas durante os intervalos das aulas de estágio curricular. Já no curso de Ciências Sociais as entrevistas foram feitas no período noturno, na universidade, antes do início das aulas.

O presente texto divide-se em duas partes: na primeira se discute as mulheres e a questão da maternidade; na segunda parte apresentam-se os dados coletados das entrevistas, a partir dos seguintes itens: o cuidado de si; a construção da carreira e as motivações; a maternidade e seus significados e a participação paterna no cuidado dos filhos.

\section{As mulheres e a maternidade}

Apesar de todas as conquistas feministas que emergiram nos últimos anos, destacando a entrada massiva das mulheres no mercado de trabalho e no ensino superior, quando o assunto é discutir cuidado dos filhos e da casa, são as mulheres ainda as mais lembradas, cobradas e responsabilizadas. Considerando-se essa distribuição pouco democrática do trabalho de cuidado que tende a implicar diretamente na vida das mulheres que desejam e precisam trabalhar fora de casa (ARAÚJO, 2006). 
Alguns discursos naturalistas do final do século XIX contribuíram para endossar a maternidade como uma característica que compreenderia a mulher em sua plenitude existencial, logo todas deveriam passar por essa experiência (MARTINS, 2004). Experiência essa que durante muito tempo funcionou como um padrão cultural feminino, responsável por reduzir as mulheres há seres naturalmente destinados à reprodução.

Essa forte representação do gênero feminino a partir da maternidade pode justificar o aumento nos últimos anos de tratamentos de fertilidade realizados por mulheres mais velhas, que depois de terem alcançado o sucesso na carreira profissional, buscam na maternidade uma realização plena (HEWLETT, 2008).

Mesmo que atualmente haja homens que se empenham em cuidar dos filhos e dividir as tarefas domésticas, a maternidade ainda pesa sobre as mulheres, especialmente para aquelas que dispõem de poucos recursos materiais para comprar os serviços de cuidado (HIRATA; GUIMARÃES, 2012).

Em relação às mulheres que se dedicam ao trabalho da maternidade, geralmente seus desempenhos são percebidos como normal, ao contrário dos homens, que quando se dedicam à paternidade, podem ser identificados como verdadeiros heróis ${ }^{36}$.

Atualmente a mídia utiliza de algumas figuras masculinas para apresentar pais que deram certo, ou seja, conscientes de suas paternidades, que quando ajudam suas esposas e participam ativamente da educação de seus filhos e filhas recebem muitos elogios e viram exemplos a serem seguidos. Logo, a representação atrelada à mulher mãe contribui para sustentar as microdesigualdades de gênero sofridas pelas mulheres que optaram pela carreira e maternidade (FABBRO, 2006, O'REILLY, 2005).

Deste modo, essa mulher elástica ${ }^{37}$ (O’REILLY, 2005) pode ser um multiplicador de desigualdades de gênero, pois contribui para reforçar um tipo ideal de mulher sempre disposta a cuidar da família. Depois que os filhos crescem, terão seus pais e mães idosas para cuidar, considerando que no Brasil as políticas de cuidado não têm sido as mais eficientes. (CAMARANO; MELO, 2010, GUEDES, 2016).

Do mesmo modo, essa representação da mulher elástica, deve ser analisada considerando-se que muitas mães, por delegar o cuidado dos filhos a outras mulheres, estão conseguindo conciliar carreira e maternidade. No entanto, é importante

\footnotetext{
${ }^{36} \mathrm{Na}$ mídia brasileira os exemplos têm sido o ator Rodrigo Hilbert e Marcos Piangers, autor do livro $O$ Papai é Pop. Eles apareceram com os/as filhos/as mostrando que são homens conscientes, pois dividem as tarefas domésticas e o cuidado das crianças.

${ }^{37}$ Elástica é a mulher que consegue exercer diversas funções ao mesmo tempo e sente-se feliz e realizada. Para mais informações ler: O’REILLY (2005).
} 
destacarmos a questão da maternidade de transferência ${ }^{38}$ e o investimento em escolinhas de tempo integral para aquelas que podem comprar os serviços de cuidado. Aquelas que não dispõem de recursos materiais para comprar esses serviços, acabam tendo pouco tempo para se qualificarem para participar do mercado de trabalho. Logo, quando se inserem no mercado tendem a vivenciar a precarização (HIRATA; KERGOAT, 2005).

Nesse sentido, é importante ressaltar o aumento de mulheres brasileiras em trabalhos informais, avaliando as dificuldades que a condição materna pode lhes exigir para participar do mercado de trabalho formal. Hirata (2005) salienta que mesmo que o trabalho feminino ainda continue concentrado em setores como serviços pessoais, saúde e educação, é relevante considerar a condição de bipolarização para se analisar a situação das mulheres no mercado de trabalho. Sobre essa diversidade do trabalho feminino, Helena Hirata compartilhando com Danielle Kergoat, destaca que:

[...] a tendência à diversificação das funções mostra, hoje, uma situação caracterizada pela bipolarização: em um extremo, profissionais altamente qualificadas com bons ganhos (engenheiras, arquitetas, médicas, professoras, gerentes, advogadas, magistradas, etc.), e, no outro, mulheres com qualificação muito baixa, baixos salários e trabalhos sem reconhecimento social (HIRATA; KERGOAT, 2005, p.116).

Nesse sentido, a terceirização do cuidado apresenta-se como uma boa opção às mães de classes médias (HIRATA; GUIMARÃES, 2012). No entanto, as mulheres de classes populares poucas opções terão em relação ao tempo para se qualificar. Quando os filhos são pequenos, isso se apresenta de forma ainda mais crítica, pois não há creches públicas e gratuitas de período integral para deixarem seus filhos.

Situação que é bem diferente se cotejada com os homens destas classes, como apontou o estudo de Maldalozzo e Blofield (2017). Nesse estudo, as autoras constatam que as mulheres de classes populares tendem a ficar na inatividade para o mercado de trabalho e com dificuldades para se qualificarem devido ao cuidado dos filhos e do trabalho doméstico, que ficam sob as suas responsabilidades. Partindo deste conflito, as autoras salientam que é preciso se pensar em políticas de coparticipação do Estado e dos pais para o cuidado dos filhos a fim reduzir os danos causados na vida das mulheres dessas classes sociais.

\footnotetext{
38 Para mais informações ler: COSTA (2002).
} 
Compartilhando desse ponto de vista, podemos verificar que ter um filho requer custos emocionais e materiais. Conforme Ferreira (2003), o período estabelecido para as licenças paternidade e maternidade, retira dúvidas de quem deve cuidar da criança nos primeiros meses de vida, portanto são ainda as mulheres as mais prejudicadas.

Durante muito tempo o destino feminino esteve vinculado à maternidade, como se essa condição fosse algo determinado biologicamente e da qual a mulher não teria como fugir. Logo, ela deveria compreender as alterações funcionais de seu corpo nas diferentes fases da gestação, sem se descuidar da beleza e da sensualidade. Nesse sentido, a maternidade era significativamente representada a partir do discurso biológico e social da passividade presente no gênero reconhecido como culturalmente feminino (SANT’ANNA, 1995; MARTINS, 2004, MARTIN, 2006).

Da mesma forma, o corpo feminino, vinculado ao destino natural da maternidade, incluiu as mulheres em papéis sociais considerados inferiores aos alocados aos homens no processo cultural. Nesse sentido, esses papéis femininos atrelados ao trabalho de cuidado foram determinados culturalmente pelo corpo biologicamente visto como feminino, tendo como exemplo maior a maternidade. Sendo ela a condição mais próxima da natureza e mais distante da racionalidade presente no gênero masculino (ORTNER, 1979).

De acordo com Porto (2011), a construção da maternidade a partir dessa dimensão simbólica atribuída ao fato biológico, foi interpretada como decorrência natural do ato sexual e da gravidez, naturalizando as mesmas crenças que orientam as relações de gênero e os valores atribuídos a cada sexo.

Foi com a publicação da obra de Simone de Beauvoir, O segundo sexo (1949), que a maternidade começou a ser vista como um constructo social, logo a maternidade designava o lugar da mulher na sociedade, ou seja, a mãe zelosa presente no espaço doméstico era responsável pelo cuidado dos filhos. Ao alocar a mulher nesta posição, o espaço público não fazia parte da vida das mulheres (SCAVONE, 2001:2004).

A inserção feminina no mercado de trabalho formal encontrou diversas barreiras de gênero, principalmente em um mercado dominado simbolicamente e majoritariamente pelos atributos de masculinidade. Segundo Scavone (2001), é possível afirmar que um dos aspectos mais evidentes na transformação da maternidade foi o rompimento com seu determinismo biológico. É a partir deste momento que a maternidade deixou de ser um destino feminino para ser escolha.

Foi o rompimento com o discurso biológico e os papéis sociais, e o tratamento da maternidade como escolha, que intensificaram as mudanças a partir das reivindicações dos movimentos feministas da segunda onda. Esses, que contribuíram 
significativamente para as mulheres se inserirem no mercado de trabalho e na educação formal como sujeitos de suas escolhas. Assim, surgem novos modelos de maternidade que englobam diversos tipos de família e relacionamentos, passando essa a ser uma questão social e não mais uma responsabilidade exclusiva da mulher.

No entanto, ainda nos deparamos com discursos que naturalizam a maternidade como função/obrigação das mulheres. Um exemplo é o que ficou evidente no estudo das autoras Schwengber e Meyer (2007) a partir de uma análise da revista Pais \& Filhos, entre os anos de 1968 e 2004, em que constataram como as mulheres ainda são representadas pela mídia como mães. De acordo com o estudo, a revista posiciona as gestantes como mulheres que necessitam desenvolver competências específicas, segundo padrões definidos, para melhor conduzirem suas gestações e cumprirem com as obrigações relativas a essa condição. A revista reforça o estereótipo da mãe amorosa e protetora que abdica da vida pública para se dedicar ao cuidado dos filhos, e durante a gestação torna-se responsável por transportar e abrigar a existência de um novo ser.

Assim, observa-se que a conciliação entre carreira e maternidade ainda é vivenciada como um período bastante trabalhoso por grande parte das mães que participam ativamente do mercado de trabalho, sendo que as universitárias também vivenciam dificuldades para lidar com esta conciliação.

Em relação à universidade, as experiências da maternidade são bastante emblemáticas: mães que relatam sobre experiências negativas nos programas de pósgraduação, moldados a partir da atual política de produtividade: produzir ou morrer (BITENCOURT, 2014, BIANCHETTI; MACHADO, 2006), inércia no currículo lattes, quando os filhos são pequenos (AQUINO, 2009). Analisando que a universidade nunca foi um lugar para crianças, pouco se discute sobre a necessidade de creches dentro do campus universitário para servidoras/es e alunas/os que têm filhos pequenos.

Partindo desta perspectiva, é importante salientar que o público da universidade mudou, considerando a expansão do ensino superior (TORINI, 2012) nos anos de 2000 e as políticas de cotas para estudantes negros, indígenas, quilombolas e de escolas públicas nos cursos de graduação e também na pós-graduação. Assim como a abertura de vários cursos no período noturno, oportunizando àquelas mulheres que não tiveram tempo para estudar, voltarem aos estudos.

Em algumas situações essas acadêmicas não têm um companheiro para dividir o cuidado dos filhos e o trabalho doméstico, e geralmente quando os parceiros participam desse cuidado, o papel da maternidade ainda pesa sobre elas, especialmente durante o período gestacional e de amamentação (AQUINO, 2009). 
Para Bianchetti e Machado (2006) o uso do tempo entre os acadêmicos/as é pensado por meio da palavra prazo, uma palavra mágica neste contexto. Especialmente entre as acadêmicas que são mães, o tempo se divide entre cumprir os prazos impostos pela faculdade e o cuidado com os filhos. Nesse aspecto o cuidar de si, tanto no âmbito físico quanto psicológico, pode ser deixado em segundo plano.

Segundo Foucault (1985) o cuidado de si abrange técnicas que permitem aos indivíduos efetuarem operações em seus próprios corpos, em suas almas, em seus pensamentos e condutas de tal modo que isto os transformem e os modifiquem, com a finalidade de alcançarem certo estado de perfeição ou felicidade.

Podemos verificar que essas operações englobam a prática de atividade física, alimentação saudável, lazer, cuidados de beleza e práticas de relaxamento e meditação. Assim como as mais diversas relações que constituem o indivíduo a partir de uma ideia de cuidar do mundo ao seu redor, contemplando o bem-estar e o equilíbrio. No entanto, a grande carga de tarefas das mulheres mães, muitas vezes, impede que essas exerçam o cuidado de si.

\section{Maternidade e os cuidados}

As mudanças na construção da identidade de gênero se deram de forma desigual, pois a socialização mudou significativamente para as mulheres. Contudo, os homens ainda continuam presos a modelos de masculinidades pautados em padrões de virilidade, logo não reivindicaram profissões vinculadas ao cuidado (ITABORAÍ; RICOLDI, 2016).

Nesse sentido, as mulheres vivenciam desvantagens em relação às suas trajetórias no mercado de trabalho, podendo sofrer limitações para ocupar postos de decisão em diversas áreas profissionais por serem responsabilizadas pelo cuidado dos filhos e da casa (AQUINO, 2009; GUEDES; ARAÚJO, 2014). Desta forma, muitas mulheres acumulam diversas funções e consequentemente se esquecem de cuidaremse.

Entre as acadêmicas, podemos observar que muitas buscam táticas para lidar com o cuidado dos filhos e o trabalho doméstico desde o curso de graduação, pois no campo acadêmico os indivíduos precisam se adequar à cultura científica e não o contrário, portanto aprender as regras do jogo para ser um bom jogador, que deve competir para ganhar. (BOURDIEU, 1975). 
Considerando que a vida acadêmica exige dedicação e tempo, conciliar essa fase com os cuidados dos filhos pode ocasionar a construção de diversos dilemas para as universitárias em relação ao uso do tempo para lidar com suas escolhas.

Os cursos de graduação exigem que as alunas tenham disponibilidade para as aulas, estágios e desenvolvimento de trabalhos, portanto quem começa a fazer um curso de graduação, necessitará se adequar a uma determinada rotina acadêmica e cumprir prazos. Esses prazos serão estabelecidos por meio da matriz curricular do curso e pelo calendário acadêmico específico, conforme a universidade analisada.

Assim, as estudantes mães necessitarão organizar o tempo do curso de graduação com os cuidados dos filhos e os cuidados de si.

Durante a observação de campo constatamos algumas características gerais de mães analisando seus cursos de graduação. Em relação às mães do curso de Medicina notamos que a faixa etária de entrada no curso varia entre 17 e 22 anos. Pelo fato de a maioria das alunas concluir o ensino médio ou cursinhos pré-vestibulares e geralmente entrar direto na universidade, trata-se de um grupo com perfil mais jovem, se comparado às estudantes do curso de Ciências Sociais que é noturno, composto de alunas sendo a maioria de trabalhadoras que tem maior número de filhos quando entra no curso (de dois a quatro). No curso de Medicina constatamos que todas as entrevistadas tinham apenas um filho.

$\mathrm{Na}$ graduação de Ciências Sociais verificamos a presença de mulheres mais velhas, que em sua maioria trabalha e estuda concomitantemente. Em geral são as que constituíram família antes de ingressar na universidade, portanto, têm filhos e agora buscam a qualificação para ingressar em uma profissão. Um grande número de entrevistadas salientou que entrou no curso tardiamente, por causa da maternidade e da família. Uma informante especificamente frisou que "a maternidade é um fator complicador para sua formação acadêmica". Prestes a jubilar no curso de Ciências Sociais, ela afirma que isso se deve ao fato de que sua prioridade é ser mãe, logo a graduação tende a ficar em segundo plano.

Rosa $^{39}$ : Por várias vezes, eu pensei em desistir. Eu penso que meu tempo já passou. Contudo, eu preciso investir [no curso], às vezes, ela [filha] requer atenção. Essa necessidade de buscar um futuro para dar para ela, então eu fico entre a cruz e a espada, por que hoje eu necessito de um financeiro, se eu não buscar esse financeiro eu não tenho como sustentar ela, mas se eu também não tiver graduação, eu vou sempre ficar pingando aqui e ali no

${ }^{39}$ Os nomes das entrevistadas deste estudo são fictícios, a fim de preservar suas identidades. 
financeiro, por que a gente sabe que hoje querendo ou não, uma graduação é o que te põe no mercado de trabalho um pouco melhor. E é muito complicado e acho que é por isso que eu tenho estendido muito o curso. Ela teve um tempo muito doente, ela interna eu tenho que ir ao médico porque ela não mamou e depois que eu a tive, parece que ser mãe - você está firme quando seu filho está firme.

Conforme a entrevistada Rosa, podemos verificar como ela sente-se dividida entre o curso de graduação e a filha, contudo, a sua fala afirma que a prioridade é a filha. Durante a entrevista, ela comenta que a filha fica doente por não ter mamado o suficiente. Evidência que afirma a sua responsabilidade com a saúde da filha. Finaliza comentando que para "estar bem" precisa que a sua filha também esteja bem, portanto apresenta a ideia da interpendência emocional entre ela e a filha.

Outra estudante de Ciências Sociais nos revelou que desistiu do primeiro curso superior que havia iniciado, pois não conseguiu conciliar o trabalho, a maternidade e a graduação. Alguns anos depois, esta mesma estudante relatou ter iniciado um curso em outra área, mas no período noturno, na tentativa de conciliar maternidade e graduação.

Desse modo, constatamos um significativo contraste entre esses dois cursos não apenas por tratar de áreas distintas (Ciências Médicas e Humanidades), mas por diferenças que refletem gênero, geração, classe social entre outros marcadores sociais.

Os cursos de graduação, por serem representados pela participação maior de estudantes jovens, têm contribuído para estudantes mais velhas não serem levadas muito a sério, se comparadas às jovens. Conforme a fala desta estudante, com idade de 54 anos, podemos perceber que além do problema de estar se qualificando tardiamente, algumas mulheres também enfrentam conflitos geracionais na universidade e constrangimentos que podem afetar suas subjetividades.

Marcela: Eu já tive um colega que falou para mim assim (por que eu sempre tirei notas e nunca reprovei em nenhuma disciplina?) 'você vai passar sempre em tudo, porque você é velha, os professores irão te dar nota' eu já ouvi isso. Aí, eu falei assim, que bom né, para alguma coisa tem que servir ser velha, falei brincando.

Constatamos que enquanto na Medicina a maternidade é uma questão para se discutir após o fim do curso de graduação, nas Ciências Sociais muitas mulheres 
priorizaram a família em detrimento da formação profissional. Muitas, inclusive, são até avós.

Também verificamos que a maternidade das alunas de ambos os cursos não foi planejada. De todas as entrevistadas, apenas uma mencionou ter planejado sua gestação. Todavia, mesmo tendo planejado, a estudante afirmou que o fato de ser mãe durante a graduação interferiu negativamente nas suas atividades acadêmicas.

No curso de Medicina os planos de residência e aperfeiçoamento na profissão continuam mesmo após o nascimento dos filhos, contudo há alterações nesses planos para quem é mãe. Uma entrevistada comentou que depois que a filha nasceu, sua prioridade é fazer residência médica na mesma cidade onde reside sua família, pois depende dela para ajudar nos cuidados com o filho.

Por outro lado, nas Ciências Sociais as estudantes mães buscam no curso de graduação uma estratégia de melhorar suas condições socioeconômicas, muito embora já sustentem integral ou parcialmente a família. Nos relatos das estudantes deste curso, constatamos que elas veem na graduação uma oportunidade de inserirem-se no mercado de trabalho como profissionais. Para elas, quem não tem nenhum tipo de curso superior ou profissionalizante é tratado quase como um "escravo" no mercado, sendo submetido às piores condições de trabalho e salários.

Apesar das dificuldades relatadas, é por uma situação profissional mais digna e melhores condições no mercado de trabalho que a maioria das estudantes de Ciências Sociais persiste na continuidade do curso de graduação. Interessante notar que essa consciência em relação à precarização do mercado de trabalho foi relatada de forma repetitiva pelas estudantes do curso de Ciências Sociais em suas entrevistas. Essas estudantes afirmaram que já sabem o que é vivenciar o mercado com pouca qualificação e ter que deixar os filhos em casa sozinhos.

Nesse sentido, podemos constatar que a análise da maternidade deve considerar as interseccionalidades ${ }^{40}$ entre as mulheres mães, a fim de se refletir como as diferentes experiências da maternidade se articulam com a realidade social da mulher contemporânea que precisa conciliar maternidade e carreira (BITENCOURT, 2013, 2017).

\footnotetext{
${ }^{40}$ Sobre as interseccionalidades nos estudos de gênero ver: Piscitelli (2008); Brah (2006).
} 


\section{Os cuidados do corpo}

Sobre o cuidado do corpo, as entrevistadas do curso de Ciências Sociais relataram que iam frequentemente ao médico. Contudo, os cuidados com alimentação, prática de exercícios físicos e uso de terapias para aliviar o estresse são mínimos em função da falta de tempo.

A fala de Juliana ilustra esse aspecto em relação ao autocuidado entre as estudantes de Ciências Sociais.

Juliana: As mulheres das Ciências Sociais não têm esse cuidado [com o corpo]. No meu caso eu achava assim, vou fazer caminhada, vou ficar cansada, não vou conseguir ler direito os textos, eu não ia fazer caminhada e ficava lendo, por que mesmo depois da atividade tem o cansaço. Eu estou falando por mim. Mas eu vejo assim, mesmo as meninas mais novas estão assim também, não têm muito cuidado, falam isso também, que não têm tempo, não é tão importante [cuidar de si].

A única exceção neste curso foi uma informante que parou de trabalhar para finalizar o curso e declarou que agora está tendo tempo para cuidar de si. Ela relatou que pratica atividades físicas e tem buscado uma alimentação mais saudável. Contudo, enfatiza em sua fala como o cuidar-se requer gastos financeiros e sabe que a maioria das mulheres do seu curso não tem. Segundo ela, "eu só consigo cuidar-me por que atualmente não trabalho fora e meu marido tem um bom salário para manter meus cuidados" (Lais).

Por outro lado, as informantes de Medicina nos informaram que mesmo tendo pouco tempo destinado ao cuidado, buscam manter uma rotina de cuidados, desde uma alimentação mais saudável até a prática de exercícios físicos na academia. Conforme a fala da estudante:

Paula: Valorizo muito [o cuidado do corpo], me alimento bem, tento ir à academia pelo menos $3 x$ por semana, o sono que acaba sendo o mais prejudicado, mas tento ter pelo menos, umas seis horas de sono por noite. Vou ao médico e faço exames periódicos também.

Essa diferença em relação à importância atribuída ao cuidado de si pode estar relacionada aos aspectos culturais de cada curso, mas também à renda das entrevistadas. Percebemos que no curso de Ciências Sociais, as mulheres têm uma 
renda menor, fator que as impossibilita de, por exemplo, fazerem academia ou irem ao salão. No curso de Medicina a renda é maior, de modo que mesmo sem tempo para cozinhar, as entrevistadas conseguem, por exemplo, comer fora de casa, manter uma alimentação mais saudável, pagar academia mensalmente e estabelecer uma frequência mínima semanal de ir ao salão de beleza para arrumar cabelos e unhas.

\section{A construção da carreira e as motivações}

Em relação às motivações para a construção da carreira todas se mostraram muito comprometidas. Nos dois cursos pesquisados ficou claro que a construção da carreira está relacionada à obtenção e manutenção de melhores condições financeiras.

$\mathrm{Na}$ Medicina houve também expressões que remetiam a realização de um sonho. A fala das entrevistadas deixou evidente que todas sempre desejaram fazer o curso de Medicina, desde muito cedo e que os seus filhos são uma motivação a mais para continuar. Em um dos relatos a entrevistada afirma que:

Joelma: uma das minhas grandes motivações é poder dar à minha filha uma melhor qualidade de vida, além de mostrar para ela (filha) que nada impede a realização de um 'sonho' quando se tem vontade e persistência e também mostrar para os meus pais que o esforço deles não foi em vão.

Percebemos que na Medicina há um envolvimento emocional significativo para estas estudantes estarem fazendo este curso. Elas veem no ser médica a realização de um sonho e um orgulho que querem dar aos seus pais, além da parte financeira.

Sofia: Minha motivação principal é meu desejo pessoal de ser médica, que foi a profissão que sempre sonhei e a qual já lutava para realizar antes de ser mãe. Em segundo lugar ter minha independência financeira e poder dar à minha filha uma boa qualidade de vida.

É importante salientar o prestígio vinculado à profissão médica, sendo a Medicina um dos cursos mais concorridos na universidade analisada. Apesar da expansão de mais cursos nos últimos anos, quem cursa Medicina, especialmente quando se é mulher, ainda tem mais reconhecimento e prestígio social se comparada, por exemplo, ao curso de Ciências Sociais na contemporaneidade (TORINI, 2012). 


\section{A maternidade e seus significados}

Por outro lado, algumas mães do curso de Ciências Sociais na autorreflexão sobre maternidade falaram que não teriam tido os filhos se pudessem escolher hoje entre "ser ou não mãe". Segundo elas, o problema é que o "filho exige muita dedicação e tempo e isso tende a atrapalhar a construção da carreira" (Juliana).

No curso de Medicina as entrevistadas também citaram que ser mãe exige muita dedicação e responsabilidade. No entanto, em suas falas não há expressão de arrependimento por terem sido mães durante a graduação.

Uma das informantes nos relatou que "como tudo na vida, a maternidade é uma escolha, por mais que não haja um planejamento na gestação, você escolhe se quer ou não quer ser mãe e que tipo de mãe você quer ser". Segundo ela, no momento que aceitou ser mãe, descobriu uma nova forma de viver, e que apesar das dificuldades, não se arrependeu de ter assumido essa nova realidade. "É algo intraduzível. Não há experiência que eu possa comparar. É, sem dúvidas, a minha prioridade desde o dia em que ela nasceu e não consigo imaginar mais qualquer passo sem pensar nela antes. É o que tenho de mais importante na vida" (Joelma).

Talvez por serem mais jovens, terem melhores condições socioeconômicas e uma rede de apoio maior, que as permite vivenciar esta fase com mais tranquilidade, estas mães têm uma visão mais romântica da maternidade.

O que não é percebido no curso de Ciências Sociais, onde as mães são mais velhas, e por isso a rede de apoio é menor e as dificuldades financeiras maiores. Demonstrando que a maternidade, muitas vezes, se torna um empecilho para a vida acadêmica. Evidência constatada na pesquisa realizada com doutorandas em Sociologia sobre maternidade e carreira (BITENCOURT, 2013).

As estudantes das Ciências Sociais relatam que renunciaram a grande parte de suas vidas por causa dos filhos. Especialmente no que tange à graduação, observamos que em sua maioria as entrevistadas criaram os filhos antes de buscar uma carreira. Isso se deve ao fato de que precisaram trabalhar para sustentar os filhos. Portanto, por não terem apoio da família, companheiro ou esse apoio não ter sido o suficiente para possibilitar que elas estudassem durante com a chegada dos filhos pequenos.

Marta: Eu acho assim que é uma responsabilidade enorme, grande, tanto que eu não planejei ter filhos e se eu tivesse como evitar, teria evitado um bom tempo. Não sei se eu teria filhos. Eles (filhos) exigem muito, você está colocando um ser no mundo, você 
tem que ser responsável por aquilo ali e eu acho que é muita responsabilidade. Nenhum dos meus filhos foi programado, eu tomava comprimido, mas para mim nunca fez efeito.

No curso de Medicina apenas uma entrevistada foi mãe antes de entrar na graduação e mesmo assim iniciou a faculdade com o filho ainda bem pequeno (dois anos). As demais engravidaram durante a graduação, sendo que nenhuma gestação foi planejada. Apenas uma entrevistada é casada, no entanto, todas têm uma rede de apoio que envolve principalmente os avós maternos da criança.

Nas falas das entrevistadas podemos verificar as dificuldades que encontram para conciliar a maternidade e a graduação. Contudo, nenhuma trancou o curso ou pensou em desistir. As dificuldades financeiras são menores e a maioria conta com ajuda da mãe para cuidar dos filhos.

No entanto, mesmo contando com essa rede de apoio, constatamos as dificuldades vivenciadas para conciliar os horários das aulas do curso de Medicina e os horários do colégio das crianças. Uma das entrevistas mencionou que teve uma discussão com uma professora, pois tinha que sair às $17 \mathrm{~h} 30$ para buscar a filha na escola e as atividades no ambulatório terminavam mais tarde.

Sofia: Não é fácil. Tudo precisa ser muito bem programado e pequenas mudanças, que são comuns na faculdade (como horário de aula, fim das atividades diárias do internato, etc) às vezes, me estressam e causam transtornos. Um exemplo prático aconteceu dias atrás, quando avisei uma professora que eu precisaria sair no máximo às $17 \mathrm{~h} 30$, pois não tinha ninguém para buscar a minha filha. A princípio, ela questionou, não gostou, chegamos a ter uma pequena discussão, mas por fim, nós mudamos o horário do início do ambulatório para dar tempo nos dias seguintes.

Outra entrevistada da Medicina comentou que com a entrada no internato ${ }^{41}$ terá que mandar o filho para a casa dos pais, que fica em outro estado em função de não haver horários estendidos nas creches e colégios e ela não ter ninguém com quem deixá-lo após a saída da escola.

\footnotetext{
41 O internato ocorre nos últimos dois anos do curso, sendo o estágio obrigatório do curso de Medicina desta Universidade.
} 


\section{A participação paterna no cuidado dos filhos}

No que tange à participação paterna no cuidado dos filhos, tivemos em cada curso uma estudante casada com o pai da criança. Ambas relataram que seus parceiros dividem as tarefas com o zelo pelas crianças, fazendo atividades escolares, levando para passear ou ao médico e cuidando das roupas e alimentação.

Uma estudante de Ciências Sociais, que não tem mais filhos pequenos, falou que o ex-marido a deixou com os quatro filhos pequenos, logo teve que cuidar de todos sozinha, só podendo iniciar a graduação depois que eles cresceram.

As outras informantes são solteiras, algumas recebem auxílio (pensão para as crianças) e uma delas não tem nenhum tipo de auxílio do pai da criança. De modo geral, em ambos os cursos, em relação às mães que são solteiras, percebemos a ausência dos pais na participação dos cuidados dos filhos.

Mesmo os pais que pagam pensão veem pouco a criança e não participam ativamente de sua vida. Tivemos um caso em que o pai não mantém a filha, contribuindo com uma pensão irrisória, que é descontada em sua folha de pagamento, por ter sido obrigado por lei pagá-la. Desta forma, percebemos que a mãe ainda é a principal responsável pelo cuidado dos filhos.

Em ambos os cursos observamos que as informantes sentem culpa por não estarem se dedicando integralmente ou suficientemente ao cuidado de seus filhos. Este sentimento de culpa tornou-se evidente no momento que questionamos sobre as dificuldades destas estudantes conciliarem graduação e maternidade.

Todas relataram que têm menos tempo do que gostariam junto aos filhos e que, muitas vezes, não estão presentes em momentos em que eles necessitam, como para fazer deveres de casa ou quando adoecem. E tentam compensar essa ausência, dando total atenção aos filhos durante o tempo livre de que dispõem.

Uma estudante do curso de Medicina salientou que "do momento que chego à casa até o momento em que ela (filha) vai dormir minha atenção é só dela" (Maria).

$\mathrm{Na}$ tentativa de compensar essas ausências encontramos um fato de desigualdade de gênero, pois é apenas depois de os filhos dormirem que elas vão desenvolver as atividades da faculdade ou cuidarem-se de alguma forma. Por causa disso, muitas vezes o tempo de sono dessas mulheres é reduzido, o que predispõe o desenvolvimento de patologias relacionadas ao esgotamento físico e mental, considerando que muitas fazem uso de psicofármacos para combater o estresse e a depressão. 


\section{Algumas Considerações}

Podemos constatar que há desigualdade de gênero nesta relação entre maternidade e universidade, especialmente entre as mães do curso de Ciências Sociais, cuja grande maioria apresentou poucos recursos materiais e ausência de uma rede de apoio para ajudá-las no cuidado com os filhos.

Dados que convergem com as pesquisas de Maldalozzo e Blofield (2017), Moe (2003), Aquino (2009); Hirata; Guimarães (2012), sendo a maternidade ainda vista e sentida como uma responsabilidade que pesa sobre as mulheres mães, diferentemente dos pais que não sofrem desigualdades de gênero tão evidentes quando o assunto é construção de uma carreira.

A necessidade de reflexão sobre o lugar da maternidade na universidade é relevante e necessária, pois a mãe trabalhadora geralmente faz o trabalho que socialmente não é valorizado.

Os tipos de trabalho que socialmente têm sido delegados às mulheres por justificativas atreladas a existência de uma segregação de papeis sociais, estão inscritos em corpos que por uma ordem de gênero, ainda são poucos questionados por muitas mulheres, pois a responsabilidade com os filhos presentes em suas falas neste estudo evidenciam que o filho é da mãe (FERREIRA, 2003).

A maioria das mulheres mães entrevistadas apresenta dificuldades em cuidarse. Muitas vezes, a necessidade de corresponder ao ideal de maternidade historicamente representado tem afetado suas subjetividades, considerando-se que muitas pensam em desistir dos estudos, pois não recebem apoio dos pais de seus filhos e do Estado para ajudar no cuidado com seus filhos. Logo, sentem dificuldades de pensarem sobre si, pois dizem não ter tempo.

Tal situação tem afetado diretamente suas subjetividades, dada a constatação de desigualdade de gênero referente à construção de uma carreira profissional quando comparada aos pais de suas crianças. Não existirem creches públicas e gratuitas para essas mães na universidade, comprova que a estrutura não é adequável às necessidades da família brasileira, pois há ainda mulheres que desejam ter filhos. Contudo, a maternidade não deve e não pode ficar sobre sua total responsabilidade neste cenário de expressiva entrada das mulheres no ensino superior e no mercado de trabalho. 


\title{
Motherhood fOR SELF-CARE: Challenges fOR BUILDING GENDER EQUTTY
}

\begin{abstract}
The growing insertion of women in higher education and in the labor market in the recent decades contributes to reinforce some dilemmas in the construction of gender equity, which reflects the use of time for women to study, work, care for the family and take care of themselves. From this perspective, this work aims to identify how university women deal with motherhood and career building during the graduation phase. For this purpose, field work was carried out in two undergraduate courses and 10 semi-structured interviews were conducted in depth with students. We concluded that the vast majority of mothers present difficulties in reconciling motherhood and studies, some of them think of giving up their studies because they do not have a support network, just as there are no public policies which recognize the participation of the mother women in Brazilian universities.
\end{abstract}

KEYWORDS: Motherhood. Care. Gender Inequality. Gender Equity.

\section{LA MATERNIDAD PARA UN CUIDADO DE SI: DESAFÍOS PARA LA CONSTRUCCIÓN DE LA EQUIDAD DE GÉNERO}

RESUMEN: La creciente inserción femenina en la educación superior y en el mercado laboral en las últimas décadas contribuye a reforzar algunos dilemas en la construcción de la equidad de género, reflejados en el uso del tiempo para que las mujeres estudien, trabajen, cuiden de la familia y de sí mismas. A partir de esta perspectiva, este trabajo tiene como objetivo identificar cómo las mujeres universitarias cómo las mujeres se ocupan de la maternidad y la construcción de la carrera durante los estudios de grado. Para esto se hizo trabajo de campo en dos cursos de graduación y se realizaron diez entrevistas semiestructuradas con estudiantes con carácter de profundidad. Concluimos que la gran mayoría de las madres presenta dificultades para conciliar maternidad y estudios, algunas de ellas piensan en desistir por no contar con una red de apoyo, asimismo se evidencia la ausencia de políticas públicas que reconozcan la participación de la mujer madre en las universidades brasileñas.

PALABRAS CLAVE: Maternidad. Cuidado. Desigualdad de género. Equidad de género. 
Referências

AQUINO, Estela Maria. Gênero e Ciência no Brasil: Contribuições para pensar a ação política na busca de equidade. In: HEILBORN, Maria Luiza et al (Org.). Sexualidade, Reprodução e Saúde. Rio de Janeiro: Editora FGV, 2009.

ARAÚJO, Emília. O doutoramento: a odisseia de uma fase da vida. Lisboa: Colibri, 2006.

BEAUVOIR, Simone. Le Deuxième Sexe. Paris: Gallimard, 1949.

BIANCHETTI, Lucídio; MACHADO, Ana Maria Netto. A bússola do escrever. Desafios e estratégias na orientação e escrita de teses e dissertações. São Paulo/Florianópolis: Cortez / Editora da UFSC, 2006.

BITENCOURT, Silvana Maria. Maternidade e universidade: desafios para a construção da igualdade de gênero. In: ENCONTRO ANUAL DA ANPOCS, 41 , Anais. Caxambu: Ed. ANPOCS, 2017.

. Os efeitos das políticas de produtividade para as novas gerações de acadêmicas na fase do doutorado. Estudos de Sociologia, Araraquara, n.37, v.19, p.451-468 jul.-dez. 2014.

Maternidade e carreira: reflexões de acadêmicas na fase de doutorado. Jundiaí: Paco, 2013.

BOURDIEU, Pierre. The specifity of the scientific field and the social conditions of the progress of reason. Social Science Information, London, v.14, n.6, p.19-47, 1975.

BRAH, Avtar. Diferença, diversidade, diferenciação. Cadernos Pagu, n.26, p.329365, 2006.

CAMARANO, Ana Amélia; MELLO, Juliana Leitão. Cuidados de Longa duração no Brasil: o arcabouço legal e as ações governamentais. In: CAMARANO, Ana, Amélia. (Org.). Cuidados de longa duração para a população idosa: um novo risco social a ser assumido? Rio de Janeiro: Ipea, 2010. 
COSTA, Suely Gomes. Proteção social, maternidade transferida e lutas pela saúde reprodutiva. Estudos Feministas, Florianópolis, n.2, v.10, p.301-323, 2002.

FABBRO, Márcia Regina Cangiani. Mulher e trabalho: problematizando o trabalho acadêmico e a maternidade. Tese (Doutorado em Educação.) - Faculdade de Educação, Universidade Estadual de Campinas, 2006.

FERREIRA, Virgínia do Carmo. Relações sociais de sexo e segregação do emprego: uma análise da feminização dos escritórios em Portugal. Tese (Doutorado em Sociologia.) - Faculdade de Economia, Universidade de Coimbra, 2003.

FOUCAULT, Michel. História da sexualidade 3. O cuidado de si. Rio de Janeiro: Edições Graal, 1985.

GUEDES, Moema. Percepções sobre o papel do Estado, trabalho produtivo e trabalho reprodutivo: uma análise do Rio de Janeiro. Cadernos Pagu, Campinas, n.47, p.519$540,2016$.

GUEDES, Moema; ARAÚJO, Clara. Desigualdade de gênero nos espaços das mulheres. In: GONÇALVES, Elaine; VANNUCHI, Maria Lucia; TROPIA, Patrícia V.; TOSTA, Tania L.D. (Org.) Iguais? Gênero, trabalho e lutas sociais. Goiânia: Ed. da PUC, Goiás, 2014.

HEWLETT, Sylvia Ann. Maternidade tardia: mulheres profissionais em busca de realização plena. São Paulo: Novo Século, 2008.

HIRATA, Helena. Globalização, trabalho e gênero. Revista Políticas Públicas, São Luís, n. 1, v.9, p.111-128, jul./dez. 2005.

HIRATA, Helena; GUIMARÃES, Nadya Araujo Guimarães. Cuidado e cuidadoras: as várias faces do trabalho do Care. São Paulo: Atlas, 2012.

HIRATA, Helena, KERGOAT, Danièle. Les paradigmes sociologiques à l'épreuve des catégories de sexe: quel renouvellement de l'épistémologie du travail? In: DURAND J.P. et LINHART D. (Org.). Les ressorts de la mobilisation au travail. Toulouse: Octarès, 2005. 
TABORAÍ, Nathalie Reis; RICOLDI, Arlene Martinez. Até onde caminhou a revolução de gênero no Brasil? Implicações demográficas e questões sociais. Belo Horizonte: ABEP, 2016.

MARTINS, Ana Paula Vosne. Visões do Feminino: A medicina da Mulher nos séculos XIX e XX. Rio de Janeiro: Editora da Fiocruz, 2004.

MARTIN, Emily. A mulher no corpo: uma análise cultural da reprodução. Rio de Janeiro: Garamond, 2006.

MALDALOZZO, Regina; BLOFIELD, Merike. Como famílias de baixa renda em São Paulo conciliam trabalho e família? Estudos Feministas, Florianópolis, n.25, v.1, p.215-240, 2017.

MOE, Karine S. Women, Family and Work: Writings on the Economics of Gender. Blackwell Publishing Ltd, 2003.

O'REILLY, A. Feminist Perspectives on Mothering: Power and Oppression. Edited by PORTER Marie; SHORT, Patricia; O'REILLY Andrea. Australian International Academic Conference on Motherhood (University of Queensland). Toronto: Women's Press, 2005.

ORTNER, Sherry. Está a Mulher para o Homem assim como a Natureza para a Cultura? In: ROSALDO, Michelle Zimbalist; LAMPHERE, Louise (org.). A Mulher, a Cultura, a Sociedade. Rio de Janeiro: Paz e Terra, 1979.

PIANGERS, Marcos. O Papai é Pop. Porto Alegre: L\&PM, 2015.

PISCITELLI, Adriana. Interseccionalidades, categorias de articulação e experiências de migrantes brasileiras. Sociedade e Cultura, n.2, v.11, jul/dez, p.263-274, 2008.

PORTO, Dora. O significado da maternidade na construção do feminino: uma crítica bioética à desigualdade de gênero. Revista Redbioética. Brasília, n.3, v.1, p.55-66, 2011.

SANT'ANNA, Denise B. Políticas do corpo, elementos para uma história das práticas corporais. São Paulo: Estação Liberdade, 1995. 
SCAVONE, Lucila. Dar a vida e cuidar da vida: feminismo e ciências sociais. São Paulo: Editora UNESP, 2004.

. A maternidade e o feminismo: diálogo com as ciências sociais. Cadernos Pagu, Campinas, v.16, p.137-150, 2001.

SCHWENGBER, Maria Simone Vione, MEYER, Dagmar E. Estermann. Educar corpos Femininos como corpos grávidos - Um Olhar de gênero sobre pais \& filhos. Gênero. Niterói, n.2, v.7, p.65-79, 2007.

SORJ, Bila; FONTES, Adriana; MACHADO, Danielle Carusi. Políticas e práticas de conciliação entre família e trabalho no Brasil. Cadernos de Pesquisa, n.132, v.37, p.573-594, 2007.

TORINI, Danilo Martins. Formação e Identidade profissional. A trajetória de egressos de Ciências Sociais. Programa de Pós-Graduação em Sociologia. Dissertação (Mestrado em Sociologia) - Faculdade de Letras, Filosofia e Ciências Humanas, Universidade de São Paulo, 2012.

Recebido em 26/05/2018.

Aprovado em 15/02/2019. 